\title{
The utility of superficial abdominal reflex in the initial diagnosis of scoliosis: a retrospective review of clinical characteristics of scoliosis with syringomyelia
}

Takahito Fujimori*, Motoki Iwasaki, Yukitaka Nagamoto, Hironobu Sakaura, Kazuya Oshima, Hideki Yoshikawa

\begin{abstract}
Background: With increasing use of magnetic resonance imaging (MRI), underlying syringomyelia is increasingly found in patients with presumed idiopathic scoliosis. To determine the indications for MRI in the differential diagnosis of scoliosis, several clinical characteristics of syringomyelia have been reported. Neurological signs, particularly abnormal superficial abdominal reflex (SAR), are important in establishing the initial diagnosis of scoliosis. However, the prevalence of abnormal SAR in patients with scoliosis and the sensitivity of this sign in predicting syringomyelia are not well known. We aimed to determine the diagnostic utility of SAR and other characteristics of syringomyelia in patients with scoliosis.

Methods: We reviewed the medical records of 93 patients with scoliosis, 90 of whom underwent corrective surgery. All patients underwent MRI to determine the presence of syringomyelia. Mean age at surgery was 12.5 years. Abnormal SAR was defined as unilateral or bilateral absence or hyporeflexia of SAR. We calculated indices of diagnostic utility of abnormal SAR for non-idiopathic scoliosis and for syringomyelia. Abnormal SAR, left thoracic curve pattern, gender, and curve flexibility were compared between scoliosis with syringomyelia and idiopathic scoliosis. Logistic regression analysis was performed with the existence of syringomyelia as the dependent variable and curve flexibility as the independent variable.

Results: Abnormal SAR was observed in 20 patients (prevalence 22\%). All 6 patients with myopathic scoliosis displayed bilateral absence of SAR. The sensitivity of abnormal SAR for non-idiopathic scoliosis was 38\%, with $96 \%$ specificity, 90\% PPV (positive predictive value), and 60\% NPV (negative predictive value). Syringomyelia was identified in 9 of the 93 patients (9.7\%); 8 of these had abnormal SAR. The sensitivity of abnormal SAR for syringomyelia in presumed idiopathic scoliosis was $89 \%$, with 95\% specificity, 80\% PPV, and 98\% NPV. Gender, abnormal neurological findings, and curve flexibility differed significantly between patients with syringomyelia and those with idiopathic scoliosis $(P<0.05)$. In the logistic regression model, the area under the receiver operating characteristic (ROC) curve was 0.79 and the cut-off value of curve flexibility for syringomyelia was $50 \%(P=0.08)$.

Conclusion: Abnormal SAR was a useful indicator not only for syringomyelia, but also for myogenic scoliosis.
\end{abstract}

\footnotetext{
* Correspondence: takahito-f@hotmail.co.jp

Department of Orthopaedic Surgery, Osaka University Graduate School of

Medicine, 2-2 Yamadaoka, Suita, Osaka 565-0871, Japan
} 


\section{Background}

Correct initial diagnosis of patients with scoliosis is important for decisions on treatment options. Misdiagnosis of scoliosis with underlying syringomyelia may result in complications following operative therapy or even brace therapy [1-3]. However, recent studies have reported that even patients with both scoliosis and syringomyelia have a small risk of neurological complications if they are neurologically normal or have a small syrinx [4-7]. Therefore, whether all patients with scoliosis should be examined by magnetic resonance imaging (MRI) remains controversial from a costeffectiveness perspective [4,6-9]. The prevalence of underlying syringomyelia in cases of "idiopathic" scoliosis also differs between previous reports (range, 2-28\%) [4,10-12]. Several indicators of syringomyelia have been reported in scoliosis patients: left thoracic curve [3,13-16], juvenile-onset scoliosis [11,15,17], rapid curve progression [3,18], pain [14], thoracic hyperkyphosis [19-21], male sex [5], and abnormal neurologic signs $[4,5,9,13,22]$. Of these indicators, neurologic signs, particularly an abnormal superficial abdominal reflex (SAR), is thought to be one of the most important clinical signs of syringomyelia[4,9]. In a study of 72 patients with scoliosis and atypical features, Morcuende reported that all patients with abnormal SAR had Arnold-Chiari malformations [9]. In a study of 327 patients with adolescent idiopathic scoliosis, Do emphasized the importance of abnormal SAR, even though the sensitivity and specificity of this sign was questionable [4]. Thus, although abnormal SAR has been regarded as an important neurological sign in the initial diagnosis of scoliosis, the prevalence of abnormal SAR and the diagnostic utility of abnormal SAR in predicting scoliosis with syringomyelia or other types of scoliosis has not been well known. We therefore examined the prevalence and diagnostic utility of abnormal SAR in all patients with scoliosis treated by a single spinal surgeon. In corrective surgery for scoliosis with syringomyelia, there is a potential risk of paraplegia: Overcorrection, tenuous blood supply, and changes in cerebrospinal fluid pressures are thought to be the causes of neurological complications $[1,3,23]$. In our experience, the curves of scoliosis with syringomyelia are likely to be more flexible than those of idiopathic scoliosis. However, few studies have reported differences in scoliosis curve flexibility relating to the presence or absence of syringomyelia. The purpose of this study was to determine the utility of abnormal SAR and curve flexibility in the initial diagnosis of scoliosis, particularly for scoliosis with syringomyelia.

\section{Methods \\ Subjects}

In this retrospective study we reviewed the medical records of 93 patients with scoliosis. Of these, 90 consecutive patients underwent corrective surgery for scoliosis and the other 3, who had syringomyelia, were followed non-operatively. Patients with adult scoliosis and degenerative scoliosis were excluded. Age was 0-3 years in 1 patient, 4-9 years in 15 patients, and 10-19 years in 77 patients. Mean age at surgery was 12.5 years (range, 3-28 years). Final diagnosis was idiopathic scoliosis in 46 patients, scoliosis with syringomyelia in 9, other neuropathic scoliosis in 3, congenital scoliosis in 9, myopathic scoliosis in 7, thoracogenic scoliosis in 5, neurofibromatosis in 3, Marfan syndrome in 3, and other symptomatic scoliosis in 8. "Idiopathic" scoliosis which means idiopathic-like scoliosis was defined as idiopathic scoliosis and scoliosis with syringomyelia. In the present study 55 patients were regarded as "idiopathic" scoliosis.

Of the 9 patients with syringomyelia, 6 underwent corrective surgery with uneventful recoveries and the other 3 patients with mild deformity were treated with corrective braces. Five of the 6 patients undergoing corrective surgery underwent neurosurgery for syringomyelia and 2 of the 3 patients with brace therapy underwent neurosurgery (foramen magnum decompression: FMD or syringosubarachnoid shunt: S-S shunt). Demographic data of the 9 patients with syringomyelia are summarized in Table 1.

\section{Neurological assessment}

Before ordering MRI, a senior orthopedic spinal surgeon (M.I.) performed detailed neurological examinations, consisting of an evaluation of sensory and motor functions, deep tendon reflexes of the lower extremities and Babinski reflex, as well as SAR. To examine SAR, patients were positioned supine on an examination table with arms relaxed along the sides of the body and the skin was lightly scratched with a blunt pin in the plane of a dermatome from the outer abdomen toward the midline. Presence of SAR was defined as clear deviation of the umbilicus toward the test side. Absence of SAR was defined as no movement of the umbilicus. Hyporeflexia of SAR was defined as less pronounced deviation than in normal cases. Normal SAR was defined as clear deviation of SAR on both sides of the abdomen, and abnormal SAR was defined as absence or hyporeflexia of SAR on one or both sides of the abdomen (including unilateral hyporeflexia or absence and bilateral hyporeflexia or absence). In addition, we calculated sensitivity, specificity, positive predictive value (PPV), and negative predictive value (NPV) of SAR for non-idiopathic scoliosis and for scoliosis with syringomyelia. 
Table 1 Demographic data of 9 patients with syringomyelia

\begin{tabular}{|c|c|c|c|c|c|c|c|c|c|}
\hline Case & 1 & 2 & 3 & 4 & 5 & 6 & 7 & 8 & 9 \\
\hline Age (years) & 28 & 8 & 12 & 9 & 14 & 16 & 6 & 11 & 12 \\
\hline Gender & M & M & $\mathrm{F}$ & $\mathrm{F}$ & F & M & $\mathrm{F}$ & M & $\mathrm{F}$ \\
\hline Abnormality & Chiari & Syrinx & Chiari & Syrinx & Chiari & Chiari & Chiari & Chiari & Chiari \\
\hline $\begin{array}{l}\text { Cobb angle } \\
\left(\left(^{\circ}\right)\right.\end{array}$ & 90 & 60 & 105 & 85 & 71 & 56 & (38) & $(23)$ & (30) \\
\hline Flexibility (\%) & 52 & 78 & 55 & 50 & 56 & 58 & None & None & None \\
\hline SAR & Bil hypo & $\mathrm{R}$ abs & $\mathrm{L}$ abs & Bil hypo & $\mathrm{L}$ abs & L hypo & $\mathrm{L}$ abs & L hypo & Norma \\
\hline Convex side & $\mathrm{rt} \mathrm{T}$ & $\mathrm{rt} \mathrm{T}$ & $\mathrm{rt} \mathrm{T}$ & rt T & It T & $\begin{array}{l}\text { rt T+ } \\
\text { lt L }\end{array}$ & It T-L & It $L$ & $\mathrm{rt} \mathrm{T}$ \\
\hline Corrective surgery & ASF & ASF & $\mathrm{ASF}+\mathrm{PSF}$ & $\mathrm{ASF}+\mathrm{PSF}$ & PSF & PSF & None & None & None \\
\hline Neurosurgery & None & SS & FMD & SS & FMD & FMD + SS & FMD & FMD & None \\
\hline
\end{tabular}

ASF, anterior spinal fusion; Chiari, Arnold-Chiari malformation with syrinx; FMD, foramen magnum decompression; It, left; L, lumbar; PSF, posterior spinal fusion; rt, right; SAR, superficial abdominal reflex; SS, syringo-subarachnoid shunt; T, thoracic; T-L, thoracolumbar

\section{Radiograph assessment}

Posteroanterior (PA) and lateral radiographs of the entire spine were taken in a standing position to evaluate deformities. Curve flexibility was calculated using the following formula: (standing angle - traction or side bending angle)/standing angle $\times 100(\%)$. Flexibility was compared between operatively-managed patients with syringomyelia and those with idiopathic scoliosis. Logistic regression and receiver operating characteristic (ROC) analysis was performed with the existence of syringomyelia as the dependent variable and curve flexibility as the independent variable.

\section{Magnetic resonance imaging}

A Signa Excite 1, 5_T system (General Electric Medical Systems, Milwaukee, WI, USA) was used to produce T1 and $\mathrm{T} 2$ weighted sagittal screening images of the cervical, thoracic and lumbar spine for all patients in the study, along with axial images of the craniocervical junction, cervicothoracic junction and thoracolumbar junction. All images were evaluated by a neurological radiologist, and by a spinal surgeon to identify hind brain and spinal cord abnormalities, recording the position of the conus medullaris and the presence or absence of syringomyelia and Arnold-Chiari malformations.

\section{Statistical analysis}

Wilcoxon rank-sum test and Fisher's exact test were applied for statistical analysis using JMP 8.0 software (SAS Institute, Cary, NC, USA), as appropriate. All tests were evaluated as two-tailed. Values of $\mathrm{P}<0.05$ were considered significant.

\section{Results}

Abnormal SAR among all patients with scoliosis

Abnormal SAR were observed in 20 patients (prevalence 22\%) (Table 2).

A: Bilateral absence of SAR.
All six patients with bilateral absence of SAR had myopathic scoliosis.

B: Unilateral absence of SAR.

Six patients had unilateral absence of SAR; 2 had absence of SAR on the side of abdominal surgery, and the other 4 patients had syringomyelia.

C: Bilateral hyporeflexia of SAR.

Five patients had bilateral hyporeflexia of SAR; one had muscular dystrophy, 2 patients had idiopathic scoliosis, and the other 2 patients had syringomyelia.

D: Unilateral hyporeflexia of SAR.

Three patients had unilateral hyporeflexia of SAR; one patient with thoracogenic scoliosis had hyporeflexia on the side of abdominal surgery, and the other 2 patients had syringomyelia.

Table 2 Abnormality of superficial abdominal reflex (20 of 93 cases; $22 \%$ )

\begin{tabular}{|c|c|c|}
\hline Abnormal SAR & $\begin{array}{l}\text { Number of } \\
\text { cases }\end{array}$ & Diagnosis \\
\hline $\begin{array}{l}\text { A: Bilateral } \\
\text { absence }\end{array}$ & 6 & 6 myopathic \\
\hline \multirow{3}{*}{$\begin{array}{l}\text { B: Unilateral } \\
\text { absence }\end{array}$} & 6 & 4 syringomyelia \\
\hline & & $\begin{array}{l}1 \text { thoracogenic (after abdominal } \\
\text { surgery) }\end{array}$ \\
\hline & & $\begin{array}{l}1 \text { myelomeningocele (after } \\
\text { abdominal surgery) }\end{array}$ \\
\hline \multirow{2}{*}{$\begin{array}{l}\text { C: Bilateral } \\
\text { hyporeflexia }\end{array}$} & 5 & 2 syringomyelia \\
\hline & & $\begin{array}{l}1 \text { Duchenne muscular dystrophy } \\
2 \text { idiopathic }\end{array}$ \\
\hline \multirow{2}{*}{$\begin{array}{l}\text { D: Unilateral } \\
\text { hyporeflexia }\end{array}$} & 3 & 2 syringomyelia \\
\hline & & $\begin{array}{l}1 \text { thoracogenic (after abdominal } \\
\text { surgery) }\end{array}$ \\
\hline
\end{tabular}

SAR, superficial abdominal reflex 
Table 3 Abnormal SAR as a predictor of non-idiopathic scoliosis in all patients

\begin{tabular}{lllll}
\hline & Non-idiopathic & Idiopathic & Total & \\
\hline Abnormal SAR & 18 & 2 & 20 & PPV 90\% \\
Normal SAR & 29 & 44 & 73 & NPV 60\% \\
Total & 47 & 46 & 93 & \\
& Sensitivity 38\% & Specificity 96\% & & \\
\hline
\end{tabular}

NPV, negative predictive value; PPV, positive predictive value; SAR, superficial abdominal reflex

Consequently, all 7 patients with myopathic scoliosis, 8 of 9 patients with syringomyelia and other 5 patients had abnormal SAR. The sensitivity of abnormal SAR for non-idiopathic scoliosis was thus $38 \%$, with $96 \%$ specificity, 90\% PPV, and 60\% NPV (Table 3). There was a significant difference in the prevalence of abnormal SAR between patients with non-idiopathic scoliosis (38\%) and those with idiopathic scoliosis $(4 \%)(\mathrm{P}<0.0001)$.

\section{Abnormal SAR in patients with syringomyelia}

Syringomyelia was found in 9 of the 93 patients (9.7\%), and 7 of these 9 patients had the Arnold-Chiari malformation. Eight of the 9 patients with syringomyelia had abnormal SAR. Only one patient (Case 9) with syringomyelia, whose subarachnoid space at the foramen magnum was relatively wide, had normal SAR (Fig. 1). The sensitivity of abnormal SAR for syringomyelia was $89 \%$, with $86 \%$ specificity, 40\% PPV, and 99\% NPV (Table 4). Prevalence of

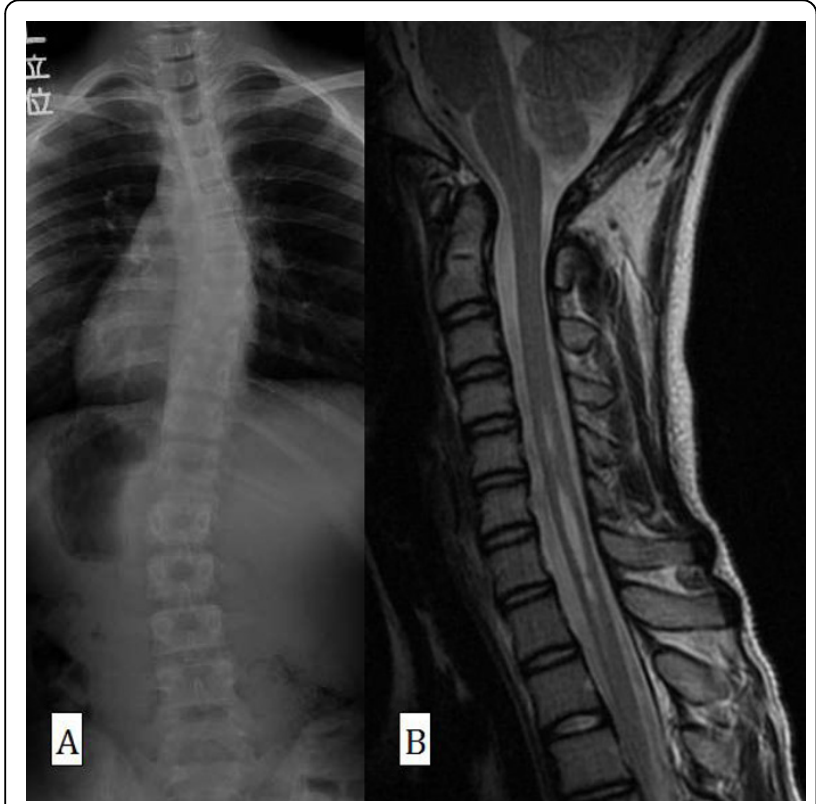

Figure 1 Posteroanterior radiograph (A) and sagittal MRI (B) in Case 9. The patient was neurologically normal. The syrinx was spindle type and the space of the cisterna magna was preserved. This patient was not suitable for FMD and was treated using an underarm brace.
Table 4 Abnormal SAR as a predictor of scoliosis with syringomyelia in all patients

\begin{tabular}{lllll}
\hline & Syringomyelia & No syringomyelia & Total & \\
\hline Abnormal SAR & 8 & 12 & 20 & PPV 40\% \\
Normal SAR & 1 & 72 & 73 & NPV 99\% \\
Total & 9 & 84 & 93 & \\
& Sensitivity 89\% & Specificity 86\% & & \\
\hline
\end{tabular}

NPV, negative predictive value; PPV, positive predictive value; SAR, superficial abdominal reflex

abnormal SAR differed significantly between those with scoliosis and syringomyelia (89\%) and those with scoliosis without syringomyelia $(14 \%)(\mathrm{P}<0.0001)$. Focusing the subjects on "idiopathic" scoliosis, the sensitivity of abnormal SAR for syringomyelia was $89 \%$, with $95 \%$ specificity, $80 \%$ PPV, and $98 \%$ NPV (Table 5).

Of the 9 patients with syringomyelia, 5 with a single major curve and 1 with a double major curve had unilateral hyporeflexia or absence of SAR. Four of the 5 patients with a single major curve showed hyporeflexia or absence of SAR on the same side as the convexity of the curve (Cases 2, 3, 7, 8), but the remaining patient did not (Case 6) (Table 1).

\section{Curve flexibility of patients with syringomyelia}

The mean preoperative Cobb angle for the 6 patients with syringomyelia who had corrective surgery was $78^{\circ}$ (range, $56-105^{\circ}$ ) and mean curve flexibility was 58\% (range, 50-78\%). Conversely, mean preoperative Cobb angle for patients with idiopathic scoliosis who had corrective surgery was $69^{\circ}$ (range, $45-128^{\circ}$ ) and mean curve flexibility was $44 \%$ (range, 11-96\%) (Table 6). Curve flexibility was significantly greater with syringomyelia than with idiopathic scoliosis $(P=0.02)$. Focusing on patients with a Cobb angle $\geq 60^{\circ}$, this difference in curve flexibility between patients with syringomyelia and those with idiopathic scoliosis was much more pronounced (Fig. 2) $(\mathrm{P}<0.0001)$. In the logistic regression model, the area under the ROC curve was 0.79 , indicating moderate discriminatory ability of curve flexibility to predict syringomyelia $(P=0.08)$. The best cut-off value of curve flexibility for syringomyelia was $50 \%$ and in this model, the sensitivity was $100 \%$, with $63 \%$ specificity, $26 \%$ PPV, and 100\% NPV (Table 7).

Table 5 Abnormal SAR as a predictor of scoliosis with syringomyelia in patients with "idiopathic" scoliosis

\begin{tabular}{lllll}
\hline & Syringomyelia & No syringomyelia & Total & \\
\hline Abnormal SAR & 8 & 2 & 10 & PPV 80\% \\
Normal SAR & 1 & 44 & 45 & NPV 98\% \\
Total & 9 & 46 & 55 & \\
& Sensitivity 89\% & Specificity 95\% & & \\
\hline
\end{tabular}

"idiopathic" included idiopathic scoliosis and scoliosis with syringomyelia 
Table 6 Curve flexibility of syringomyelia

\begin{tabular}{llll}
\hline & $\begin{array}{l}\text { Syringomyelia } \\
\text { (6 operated cases) }\end{array}$ & $\begin{array}{l}\text { Idiopathic scoliosis } \\
\text { (46 operated cases) }\end{array}$ & P \\
\hline Gender (\% male) & 44 & 4.3 & $0.02^{*}+$ \\
Age (years) & $14.5(8-28)$ & $14.1(7-21)$ & 0.44 \\
Risser sign & $2.8(0-5)$ & $3.4(0-5)$ & 0.27 \\
Curve magnitude $\left(^{\circ}\right)$ & $78(56-105)$ & $69(45-128)$ & 0.17 \\
Curve flexibility (\%) & $58(50-78)$ & $44(11-96)$ & $0.02^{*}$ \\
\hline
\end{tabular}

Values are expressed as mean (range).

*Significant difference compared to the idiopathic scoliosis group

†Fisher's exact test

\section{Other indicators for scoliosis with syringomyelia}

Four of the 9 patients with syringomyelia were male (44\%) and 5 were female (56\%). In contrast, 2 of the 46 patients with idiopathic scoliosis were male (4.3\%) and 44 were female (96\%). There was a significant gender difference between patients with syringomyelia and those with idiopathic scoliosis (Table 6) $(\mathrm{P}<0.005)$. Male sex conferred a relative risk for syringomyelia of 6.5 (CI 2.4-18).

One of the 9 patients with syringomyelia (11\%, Case 5 ) and one patient with idiopathic scoliosis (2.1\%) had an atypical left-thoracic curve pattern, but this difference was not significant. $(\mathrm{P}=0.3)$

\section{Relationship between syrinx type and neurological abnormality}

The mean syrinx length was 7.5 vertebrae and the median length was 5 vertebrae. All patients with
Table 7 Flexibility $\geq \mathbf{5 0} \%$ as a predictor of scoliosis with syringomyelia in "idiopathic" scoliosis underwent operation

\begin{tabular}{lllll}
\hline & Syringomyelia & $\begin{array}{l}\text { No } \\
\text { syringomyelia }\end{array}$ & Total & \\
\hline $\begin{array}{l}\text { Flexibility } \geq \\
50 \%\end{array}$ & 6 & 17 & 23 & PPV 26\% \\
$\begin{array}{l}\text { Flexibility }< \\
50 \%\end{array}$ & 0 & 29 & 29 & NPV \\
Total & 6 & 46 & 52 & $100 \%$ \\
& $\begin{array}{l}\text { Sensitivity } \\
100 \%\end{array}$ & Specificity $63 \%$ & & \\
& & & & \\
\hline
\end{tabular}

"idiopathic" included idiopathic scoliosis and scoliosis with syringomyelia

swelling-type syrinx were neurologically abnormal (Table 8). One patient (Case 1) with bilateral hyporeflexia of SAR declined neurological decompression surgery, but his corrective surgery, for which we selected anterior fusion, was performed without any neurological complication. The syrinx of this patient was slit type (Fig. 3). One patient with normal neurology with the exception of SAR (Case 3) also had slit-type syrinx, which was relatively short (4 vertebrae). Another patient with spindle-type syrinx (Case 9) had completely normal neurological findings and a syrinx length of 4 vertebrae (Fig. 1). However, no significant difference was found between swelling type and the other types (slit or spindle) of syrinx in terms of abnormal SAR or other neurological findings $(\mathrm{P}=0.3)$.

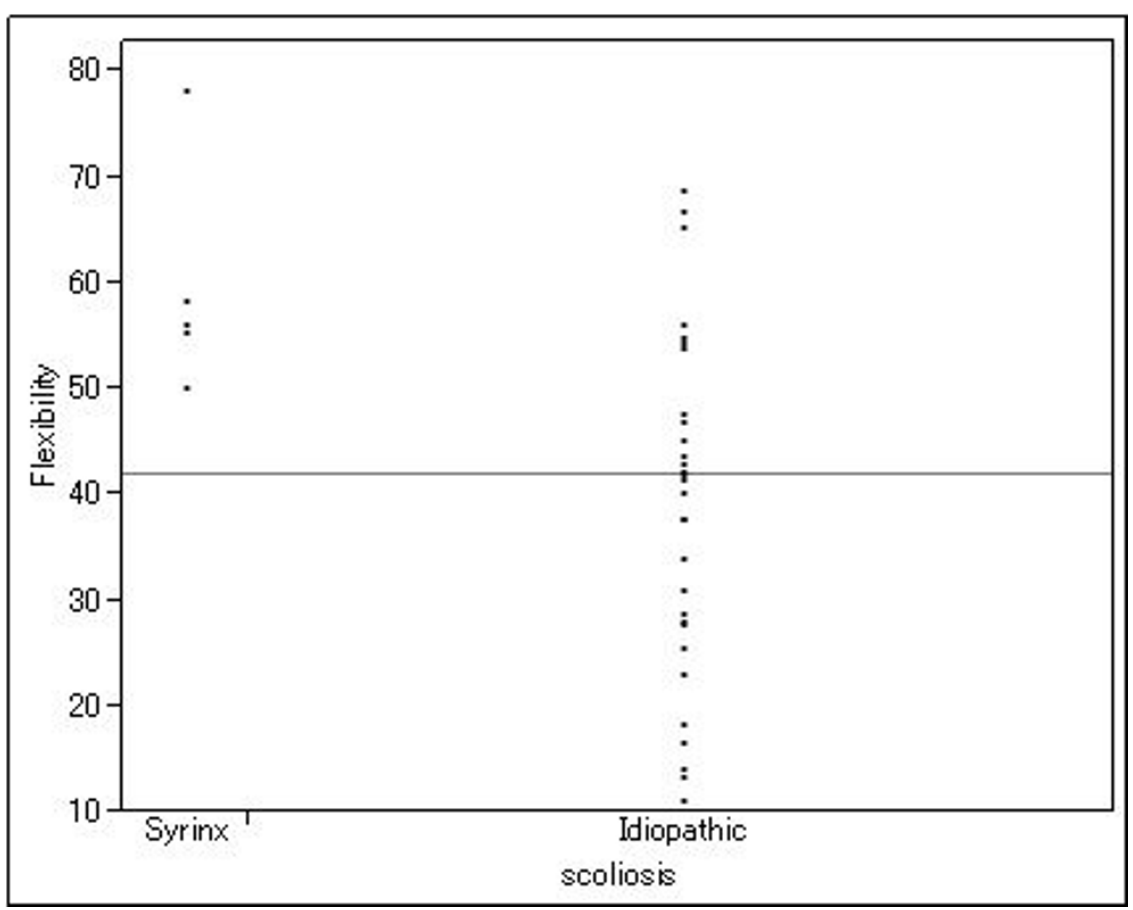

Figure 2 Distribution of curve flexibility between syringomyelia and idiopathic scoliosis (Cobb angle $\geq 60^{\circ}$ ). 
Table 8 Relationship between syrinx type and neurological abnormality

\begin{tabular}{|c|c|c|c|c|c|c|c|c|c|}
\hline Case & 1 & 2 & 3 & 4 & 5 & 6 & 7 & 8 & 9 \\
\hline Syrinx type & Slit & Swelling & Slit & Swelling & Swelling & Swelling & Swelling & Swelling & Spindle \\
\hline Syrinx level & C3-7 & Th6-9 & C5-7 & C5-8 & C5-9 & $C 2-7$ & C1-L1 & C2-Th11 & C5-8 \\
\hline $\begin{array}{l}\text { Syrinx length } \\
\text { (vertebra) }\end{array}$ & 5 & 4 & 3 & 4 & 5 & 6 & 20 & 17 & 4 \\
\hline SAR & Bil hypo & R abs & $L$ abs & Bil hypo & $\mathrm{L}$ abs & L hypo & $\mathrm{L}$ abs & L hypo & Normal \\
\hline $\begin{array}{l}\text { Other neurological } \\
\text { findings }\end{array}$ & $\begin{array}{l}\text { Bil Babinski } \\
\text { reflex }\end{array}$ & $\begin{array}{l}\text { Hyper of L/ } \\
E\end{array}$ & None & $\begin{array}{l}\text { Hyper of L/ } \\
E\end{array}$ & Hypo of L/E & $\begin{array}{l}\text { Hyper of } \\
\text { ATR }\end{array}$ & Hypo of L/E & $\begin{array}{l}\text { Headache } \\
\text { SD of left L/E }\end{array}$ & None \\
\hline
\end{tabular}

abs, absence; ATR, Achilles tendon reflex; Bil, bilateral; hyper, hyperreflexia; hypo, hyporeflexia; L, left; L/E, lower extremities; R, right; SAR, superficial abdominal reflex; SD, sensory disturbance

\section{Discussion}

A potential risk of neurologic complications has been reported when corrective surgery is performed for patients with scoliosis and syringomyelia [1-3]. Several studies have found that neurosurgery before corrective surgery reduces the risk of neurological complications and improves or stabilizes the curve, particularly in patients younger than 10 years old [24-29]. Previous reports have agreed with the consensus that MRI should be performed for infantile and juvenile scoliosis [10-12]. However, the necessity of MRI for "adolescent idiopathic" scoliosis remains controversial [11,30-32]. Some studies have suggested that MRI is not indicated in "adolescent idiopathic" scoliosis if the patients are neurologically normal $[4,6,7]$. Inoue reported that only one of 12 neurologically asymptomatic patients with

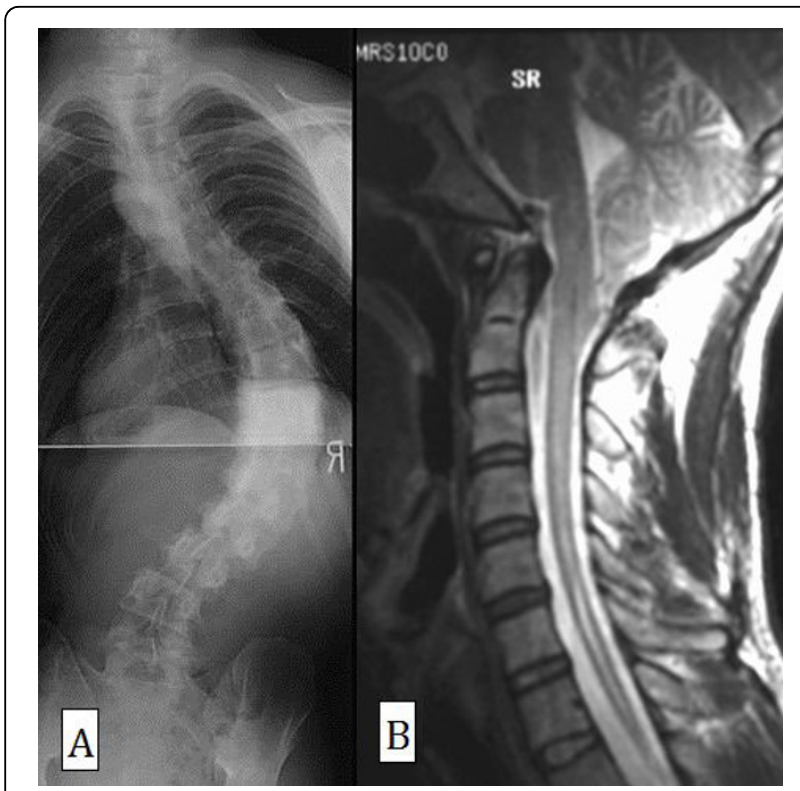

Figure 3 Posteroanterior radiograph (A) and sagittal MRI (B) in Case 1. This patient had bilateral hyporeflexia of SAR and declined neurological decompression surgery, but anterior fusion was performed without any neurological complication. The Cobb angle was $90^{\circ}$ and curve flexibility was $52 \%$. The syrinx was slit type. syringomyelia and scoliosis encountered neurological complications [5]. However, once paraplegia occurred, the prognosis was very poor. We believe corrective surgery for scoliosis should be performed with utmost care so as to minimize the risk of neurological complications. Of the neurological abnormalities thought to indicate syringomyelia, SAR is considered one of the most important [4,9]. However, in early studies, it was unclear how often patients with syringomyelia had normal SAR and how often patients with normal SAR had syringomyelia [13,22]. In Saifuddin's prospective study of 73 patients with "presumed idiopathic scoliosis", the prevalence of abnormal SAR was $11 \%$. Saifuddin concluded that unilateral absence of SAR was a significant sign suggestive of syringomyelia and that bilateral absence of SAR might also be associated with neuraxis anomalies [32]. Morduende reported that 11 patients (15\%) of 72 patients with atypical features had abnormality on MRI. In their report, 5 of the 11 patients with abnormal SAR had MRI abnormality and therefore, abnormal SAR had a sensitivity of $45 \%$ and PPV of $45 \%$. They concluded that the importance of SAR could not be overemphasized $[8,9,31]$. However, as a limitation of these studies, they might have differed in their definition of "idiopathic" or "abnormal SAR". If patients without any indicators of syringomyelia were regarded as genuine "idiopathic" cases, this might increase the PPV of SAR. Some studies have reported that absence or hyporeflexia can occur in normal individuals [33]. In the present study, "idiopathic" scoliosis included 46 patients with idiopathic scoliosis and 9 patients with scoliosis and syringomyelia. Data from previous studies regarding asymmetric SAR as abnormal in "idiopathic" scoliosis and those from the present study are listed in Table 9. The sensitivity of abnormal SAR for syringomyelia in the present study was higher than that of previous studies, partly because we included bilateral absence and hyporeflexia of SAR as abnormal signs. When considering SAR as a screening test, sensitivity is more important than PPV, because final diagnosis can be made by MRI. Therefore, it could be recommended that subtle findings such as bilateral absence or hyporeflexia of SAR should 
Table 9 Diagnostic utility of SAR in "idiopathic" scoliosis

\begin{tabular}{llllll}
\hline & $\begin{array}{l}\text { Sensitivity } \\
\text { (\%) }\end{array}$ & $\begin{array}{l}\text { Specificity } \\
\text { (\%) }\end{array}$ & $\begin{array}{l}\text { PPV } \\
\text { (\%) }\end{array}$ & $\begin{array}{l}\text { NPV } \\
\text { (\%) }\end{array}$ & N \\
\hline Inoue $(2004)^{*}$ & 34 & 97 & 71 & 87 & 250 \\
Saifuddin (2005) * & 22 & 90 & 25 & 89 & 73 \\
Present study & 89 & 95 & 80 & 98 & 55
\end{tabular}

$\mathrm{N}$, number of patients; NPV, negative predictive value; PPV, positive predictive value; SAR, superficial abdominal reflex * Abnormal SAR means asymmetry

be regarded as abnormal to give a useful screening test. In the present study, we found that abnormal SAR (defined as unilateral or bilateral absence of SAR or hyporeflexia as found by a single experienced examiner) yielded $89 \%$ sensitivity for syringomyelia. Furthermore, if SAR of a patient with scoliosis is abnormal, the patient has a $90 \%$ of probability of being non-idiopathic scoliosis (Table3). If patients with scoliosis had abnormal SAR, we could recommend physicians to check MRI of the whole spine in order to differentiate syringomyelia as well as to check myogenic enzyme in order to differentiate myopathy.

Some studies have reported the relationship between syrinx type and neurological findings or radiographic characteristics $[5,34,35]$. Inoue reported that all patients with swelling-type syrinx had some abnormal findings and our results supported these findings. In our study, male sex was a risk factor for syringomyelia with a relative risk of 6.5 (CI 2.4-18). However, there was no significant difference in left-thoracic curve pattern between patients with syringomyelia and those with idiopathic scoliosis $(\mathrm{P}=0.3)$. When reporting a good prognostic model for abnormal MRI, Morcuende et al. reported that left-thoracic curve pattern by itself may not be suggestive of MRI abnormality [9]. They concluded that left-thoracic curve pattern was associated with abnormal MRI when combined with neurologic abnormality or a severe curve despite immaturity. Our findings corresponded with theirs.

To our knowledge, there have been no previous reports describing the relationship between curve flexibility and syringomyelia. Some authors have alerted clinicians to the risk of paraplegia due to overcorrection or vulnerability of the spinal cord in corrective surgery for scoliosis with syringomyelia $[1,3,23]$. Generally, increasing age and larger Cobb angle make the curve less flexible [36]. However, in the current study, curve flexibility of patients with syringomyelia was significantly greater than that of those with idiopathic scoliosis, although mean age and Cobb angle of patients with syringomyelia were larger than those of patients with idiopathic scoliosis $(P=0.02)$. This suggests that patients with scoliosis and syringomyelia have a more flexible curve than those with idiopathic scoliosis. The logistic regression model was close to being significant $(\mathrm{P}=0.08)$. Based on this logistic regression analysis, curve flexibility $\geq 50 \%$ could be another risk of syringomyelia. Although we cannot explain the pathophysiology of hyperflexibility in syringomyelia, any abnormality in the pyramidal tract would make the curve more flexible in scoliosis with syringomyelia than in idiopathic scoliosis.

\section{Conclusions}

The sensitivity of abnormal SAR for non-idiopathic scoliosis was $38 \%$ with $96 \%$ specificity, $90 \%$ PPV, and $60 \%$ NPV. All cases of myopathic scoliosis had bilateral absence of SAR. There were significant differences between patients with syringomyelia and those with idiopathic scoliosis in gender, abnormal neurological findings (SAR), and curve flexibility. The sensitivity of abnormal SAR for syringomyelia in patients with "idiopathic " scoliosis was $89 \%$, with $95 \%$ specificity, $80 \%$ PPV, and $98 \%$ NPV. Curve flexibility $\geq 50 \%$ could be another risk of syringomyelia.

\section{Acknowledgements}

The authors wish to thank Dr. Serena S. Hu from the Department of Orthopedic Surgery at the University of California, San Francisco, for critical reading of the manuscript. Editing services were provided by Forte Science Communications, Japan.

\section{Authors' contributions}

All authors read and approved the manuscript, which has not been submitted or published anywhere else. TF and MI designed the study. HS, $\mathrm{KO}$, and $\mathrm{YN}$ revised it critically. All authors read and approved the final manuscript.

\section{Competing interests}

The authors declare that they have no competing interests.

Received: 15 April 2010 Accepted: 26 August 2010

Published: 26 August 2010

\section{References}

1. Huebert HT, MacKinnon WB: Syringomyelia and scoliosis. J Bone Joint Surg Br 1969, 51:338-343.

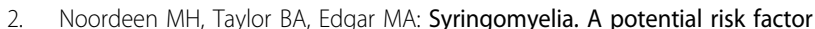
in scoliosis surgery. Spine (Phila Pa 1976) 1994, 19:1406-1409.

3. Nordwall A, Wikkelso C: A late neurologic complication of scoliosis surgery in connection with syringomyelia. Acta Orthop Scand 1979, 50:407-410.

4. Do T, Fras C, Burke S, Widmann RF, Rawlins B, Boachie-Adjei O: Clinical value of routine preoperative magnetic resonance imaging in adolescent idiopathic scoliosis. A prospective study of three hundred and twenty-seven patients. J Bone Joint Surg Am 2001, 83-A:577-579.

5. Inoue M, Minami S, Nakata Y, Otsuka Y, Takaso M, Kitahara H, Tokunaga M, Isobe K, Moriya H: Preoperative MRI analysis of patients with idiopathic scoliosis: a prospective study. Spine (Phila Pa 1976) 2005, 30:108-114.

6. Maiocco B, Deeney VF, Coulon R, Parks PF Jr: Adolescent idiopathic scoliosis and the presence of spinal cord abnormalities. Preoperative magnetic resonance imaging analysis. Spine (Phila Pa 1976) 1997, 22:2537-2541.

7. Winter RB, Lonstein JE, Heithoff KB, Kirkham JA: Magnetic resonance imaging evaluation of the adolescent patient with idiopathic scoliosis before spinal instrumentation and fusion. A prospective, double-blinded study of 140 patients. Spine (Phila Pa 1976) 1997, 22:855-858.

8. Charry O, Koop S, Winter R, Lonstein J, Denis F, Bailey W: Syringomyelia and scoliosis: a review of twenty-five pediatric patients. J Pediatr Orthop 1994, 14:309-317. 
9. Morcuende JA, Dolan LA, Vazquez JD, Jirasirakul A, Weinstein SL: A prognostic model for the presence of neurogenic lesions in atypical idiopathic scoliosis. Spine (Phila Pa 1976) 2004, 29:51-58.

10. Dobbs MB, Lenke LG, Szymanski DA, Morcuende JA, Weinstein SL, Bridwell $\mathrm{KH}$, Sponseller PD: Prevalence of neural axis abnormalities in patients with infantile idiopathic scoliosis. J Bone Joint Surg Am 2002, 84A:2230-2234.

11. Evans SC, Edgar MA, Hall-Craggs MA, Powell MP, Taylor BA, Noordeen HH: MRI of 'idiopathic' juvenile scoliosis. A prospective study. J Bone Joint Surg Br 1996, 78:314-317.

12. Gupta $P$, Lenke $L G$, Bridwell $K H$ : Incidence of neural axis abnormalities in infantile and juvenile patients with spinal deformity. Is a magnetic resonance image screening necessary? Spine (Phila Pa 1976) 1998, 23:206-210.

13. Arai S, Ohtsuka $Y$, Moriya $H$, Kitahara H, Minami S: Scoliosis associated with syringomyelia. Spine (Phila Pa 1976) 1993, 18:1591-1592.

14. Barnes PD, Brody JD, Jaramillo D, Akbar JU, Emans JB: Atypical idiopathic scoliosis: MR imaging evaluation. Radiology 1993, 186:247-253.

15. Farley FA, Song KM, Birch JG, Browne R: Syringomyelia and scoliosis in children. J Pediatr Orthop 1995, 15:187-192.

16. Wu L, Qiu Y, Wang B, Zhu ZZ, Ma WW: The left thoracic curve pattern: a strong predictor for neural axis abnormalities in patients with "idiopathic" scoliosis. Spine (Phila Pa 1976) 2010, 35:182-185.

17. Lewonowski K, King JD, Nelson MD: Routine use of magnetic resonance imaging in idiopathic scoliosis patients less than eleven years of age. Spine (Phila Pa 1976) 1992, 17:S109-116.

18. Baker AS, Dove J: Progressive scoliosis as the first presenting sign of syringomyelia. Report of a case. J Bone Joint Surg Br 1983, 65:472-473.

19. Bradley LJ, Ratahi ED, Crawford HA, Barnes MJ: The outcomes of scoliosis surgery in patients with syringomyelia. Spine (Phila Pa 1976) 2007, 32:2327-2333.

20. Ouellet JA, LaPlaza J, Erickson MA, Birch JG, Burke S, Browne R: Sagittal plane deformity in the thoracic spine: a clue to the presence of syringomyelia as a cause of scoliosis. Spine (Phila Pa 1976) 2003, 28:2147-2151.

21. Qiu Y, Zhu Z, Wang B, Yu Y, Qian B, Zhu F: Radiological presentations in relation to curve severity in scoliosis associated with syringomyelia. J Pediatr Orthop 2008, 28:128-133.

22. Zadeh HG, Sakka SA, Powell MP, Mehta MH: Absent superficial abdominal reflexes in children with scoliosis. An early indicator of syringomyelia. J Bone Joint Surg Br 1995, 77:762-767.

23. Phillips WA, Hensinger RN, Kling TF Jr: Management of scoliosis due to syringomyelia in childhood and adolescence. J Pediatr Orthop 1990, 10:351-354.

24. Ozerdemoglu RA, Transfeldt EE, Denis F: Value of treating primary causes of syrinx in scoliosis associated with syringomyelia. Spine (Phila Pa 1976) 2003, 28:806-814.

25. Ghanem IB, Londono C, Delalande O, Dubousset JF: Chiari I malformation associated with syringomyelia and scoliosis. Spine (Phila Pa 1976) 1997, 22:1313-1317, discussion 1318.

26. Yeom JS, Lee CK, Park KW, Lee JH, Lee DH, Wang KC, Chang BS: Scoliosis associated with syringomyelia: analysis of MRI and curve progression. Eur Spine J 2007, 16:1629-1635.

27. Bhangoo R, Sgouros S: Scoliosis in children with Chiari I-related syringomyelia. Childs Nerv Syst 2006, 22:1154-1157.

28. Schlesinger EB, Antunes $\mathrm{J}$, Michelsen WJ, Louis KM: Hydromyelia: clinical presentation and comparison of modalities of treatment. Neurosurgery 1981, 9:356-365.

29. Eule JM, Erickson MA, O'Brien MF, Handler M: Chiari I malformation associated with syringomyelia and scoliosis: a twenty-year review of surgical and nonsurgical treatment in a pediatric population. Spine (Phila Pa 1976) 2002, 27:1451-1455.

30. Gupta R, Sharma R, Vashisht S, Ghandi D, Jayaswal AK, Dave PK, Berry M: Magnetic resonance evaluation of idiopathic scoliosis: a prospective study. Australas Radiol 1999, 43:461-465.

31. Shen WJ, McDowell GS, Burke SW, Levine DB, Chutorian AM: Routine preoperative MRI and SEP studies in adolescent idiopathic scoliosis. $J$ Pediatr Orthop 1996, 16:350-353.

32. Saifuddin A, Tucker S, Taylor BA, Noordeen MH, Lehovsky J: Prevalence and clinical significance of superficial abdominal reflex abnormalities in idiopathic scoliosis. Eur Spine J 2005, 14:849-853.
33. Yngve D: Abdominal reflexes. J Pediatr Orthop 1997, 17:105-108.

34. Ono A, Ueyama K, Okada A, Echigoya N, Yokoyama T, Harata S: Adult scoliosis in syringomyelia associated with Chiari I malformation. Spine (Phila Pa 1976) 2002, 27:E23-28.

35. Ozerdemoglu RA, Denis F, Transfeldt EE: Scoliosis associated with syringomyelia: clinical and radiologic correlation. Spine (Phila Pa 1976) 2003, 28:1410-1417.

36. Deviren V, Berven S, Kleinstueck F, Antinnes J, Smith JA, Hu SS: Predictors of flexibility and pain patterns in thoracolumbar and lumbar idiopathic scoliosis. Spine (Phila Pa 1976) 2002, 27:2346-2349.

doi:10.1186/1748-7161-5-17

Cite this article as: Fujimori et al.: The utility of superficial abdominal reflex in the initial diagnosis of scoliosis: a retrospective review of clinical characteristics of scoliosis with syringomyelia. Scoliosis 2010 5:17.

\section{Submit your next manuscript to BioMed Central and take full advantage of:}

- Convenient online submission

- Thorough peer review

- No space constraints or color figure charges

- Immediate publication on acceptance

- Inclusion in PubMed, CAS, Scopus and Google Scholar

- Research which is freely available for redistribution

Submit your manuscript at www.biomedcentral.com/submit
Biomed Central 